\title{
Role of the viaB locus in synthesis, transport and expression of Salmonella typhi Vi antigen
}

\author{
Isabelle Virlogeux, Hervé Waxin, Chantal Ecobichon and \\ Michel Y. Popoff
}

Institut Pasteur, Unité des Entérobacteries, Unité INSERM 389, 28 rue du Docteur Roux, 75724 Paris Cedex 15, France

\author{
Author for correspondence: Michel Y. Popoff. Tel: +331456883 46. Fax: +33145688837. \\ e-mail: mypof@pasteur.fr
}

The Vi antigen is a capsular polysaccharide expressed by Salmonella typhi, the agent of human typhoid fever. Expression of this antigen is controlled by the viaA and viaB chromosomal loci. The viaB locus is composed of 11 genes designated tviA-tviE (typhi Vi), vexA-vexE ( $V i$ antigen export) and ORF11. We constructed S. typhi Ty2 strains carrying non-polar mutations in ten genes located at the viaB locus and examined the individual contribution of each gene to Vi phenotype. Phenotypes of the mutants and complementation experiments suggested that synthesis of $\mathrm{Vi}$ antigen monomer was catalysed by the TviB and TviC polypeptides. Subsequent polymerization of the polysaccharide might be catalysed by the TviE protein, but required functional TviD product. Proteins encoded by vexA, vexB and vexC directed transport of the polymer to the bacterial cell surface. Anchoring of the Vi antigen at the bacterial cell surface was dependent of the VexE protein. The TviA protein was not essential for Vi polymer synthesis. However, disruption of the tviA gene on S. typhi Ty2 chromosome strongly decreased expression of Vi antigen. This defect was fully complemented by providing tviA in trans on a recombinant plasmid. By using lacZ transcriptional fusions, it was shown that the TviA product positively regulated co-transcription of the tviA and tviB genes from a promoter located upstream of tviA. Moreover, we showed that a tviAB-lacZ fusion was not expressed in a viaA (rcsB) mutant of S. typhi. However, expression of the tviAB-lacZ fusion was restored in this viaA mutant either by the rcsB gene of Escherichia coli, or by the tviA gene of S. typhi when present in high copy number. This suggested that the tviA and viaA products could be involved in the same regulatory pathway modulating $\mathrm{Vi}$ antigen expression in S. typhi. Together these results demonstrated that proteins encoded by the viaB locus are not only involved in Vi polymer synthesis and translocation of the polysaccharide to the bacterial cell surface, but also in regulation of $\mathrm{Vi}$ antigen expression in S. typhi.

Keywords: Salmonella typhi Vi antigen, synthesis, transport, regulation, expression

\section{INTRODUCTION}

The Vi antigen of Salmonella typhi, the agent of human typhoid fever, is a capsular polysaccharide discovered by Felix \& Pitt (1934). This polysaccharide is a linear homopolymer of $\alpha$-1,4 2-deoxy-2-N-acetylgalactosamine uronic acid variably $\mathrm{O}$-acetylated at the $\mathrm{C} 3$ position (Heyns \& Kiessling, 1967; Daniels et al., 1989). All strains of $S$. typhi and Salmonella paratyphi $\mathrm{C}$, as well as a few strains of Salmonella dublin and Citrobacter freundii, are capable of expressing Vi antigen (Felix \& Pitt, 1936; Baker et al., 1959; Le Minor \& Nicolle, 1964). Expression of $\mathrm{Vi}$ antigen is controlled by two widely separated loci, via $A$ and viaB, located at 43 and 92 min on the chromosome of $S$. typhi, respectively (Johnson et al., 1965; Johnson \& Baron, 1969; Snellings et al., 1977). Functional via $A$ genes are present not only in Vi-expressing strains of Salmonella and Citrobacter, but also in Escherichia coli (Johnson \& Baron, 1969). In contrast, the viaB locus is specific to Vi-expressing strains (Snellings et al., 1977). Acquisition of the viaB region by $E$. coli results in a $\mathrm{Vi}$ positive phenotype (Johnson \& Baron, 1969; Kolyva et al., 1992). In S. typhi, the via $A$ locus which is allelic to $\operatorname{rcs} B$, a positive regulator of capsule synthesis in $E$. coli 
(Gottesman \& Stout, 1991; Houng et al., 1992), and the $o m p \mathrm{R}-e n v Z$ two-component regulatory system (Pickard $e t$ al., 1994) play an important role in the regulation of $\mathrm{Vi}$ antigen synthesis.

The viaB locus of $S$. typhi appears to contain at least two regions: one involved in biosynthesis of $\mathrm{Vi}$ antigen, and the other required for translocation of the polysacharide to the cell surface (Hashimoto et al., 1991, 1993; Kolyva et al., 1992). The complete nucleotide sequence of the viaB locus of $S$. typhi strain GIFU 10007 has been determined and 11 ORFs were identified, all being transcribed in the same orientation from ORF1 to ORF11 (Hashimoto $e t$ al., 1993). ORFs 1,4 and 11 were not named by these authors. ORFs 2,3 and 5 were designated vip ( $V i$ polysaccharide synthesis) $A, B$ and $C$, respectively. ORFs $6,7,8,9$ and 10 were named vex ( $V \mathrm{i}$ antigen export) $A, B, C, D$ and $E$, respectively. Simultaneously, we reported the nucleotide sequence of the first six ORFs of the $S$. typhi strain Ty2 $v i a B$ locus which were designated tvi (typhi $V i$ ) $A, B, C$, $D, E$ and $F$ (Waxin $e t$ al., 1993). The nucleotide sequence of the first six ORFs of $S$. typhi strains GIFU 10007 and Ty 2 was found to be strictly identical. For reasons of clarity, the $11 \mathrm{ORF}$ s will be henceforth termed as follows: $t v i A, t v i B, t v i C, t v i D, t v i E$, vex $A$, vex $B, v e x C$, vex $D$, vex $E$ and ORF11, respectively (Hashimoto $e t$ al., 1993; Waxin et al., 1993; see Fig. 1). It was shown that TviB shared significant homology to the GDP-mannose dehydrogenase $\mathrm{AlgD}$ of $P_{\text {seudomonas aeruginosa and }} \mathrm{TviC}$ to glucose epimerases of prokaryotic organisms (Hashimoto et al., 1993; Waxin et al., 1993). VexA, B, C and D proteins had similarities to components of capsule transporters (Hashimoto et al., 1993; Waxin et al., 1993). In contrast, TviA, TviD, TviE and VexE proteins showed no significant similarity to previously reported protein sequences. The functions of these products remain unknown (Hashimoto et al., 1991, 1993; Kolyva et al., 1992).

The present work was designed to examine in detail the individual contribution of each gene located in the viaB locus to Vi phenotype. For this purpose, S. typhi strains carrying non-polar mutations in the genes located in the via $B$ locus were constructed. We present evidence that TviB-TviE proteins are required for Vi polymer synthesis, and Vex-VexE proteins for the translocation of the polysaccharide to the bacterial cell surface. In addition, phenotypes of non-polar mutants, complementation experiments and studies of lac $Z$ transcriptional fusions strongly suggest that the TviA protein, whilst not essential to Vi polysaccharide synthesis, is required for the expression of Vi antigen in S. typhi.

\section{METHODS}

Strains, growth conditions and plasmids. Salmonella and Citrobacter strains were from the collection of the WHO collaborating centre for Reference and Research on Salmonella (Institut Pasteur, Paris). S. typhi strain Ty2 expressed the Vi antigen and possessed the $O: 9,12$ somatic factors. $S$. typbi strain T643WSR was a via $A$ mutant which did not express the Vi antigen (Johnson et al., 1966). Presence of either Vi antigen or $0: 9$ factor on $S$. typhi strains and derivatives was assayed by slide-agglutination with specific antisera (Diagnostics Pasteur). E. coli MC1061 [araD139 D(ara-leu)-7697 rpsL galU galK D(lacIPOZY)X74] (Casadaban \& Cohen 1980) and E. coli HB101 (bsdR bsdM rec A13 sup E44 lacZ4 leuB6 pro A2 thi-1 rpsL) (Boyer \& Roulland-Dussoix, 1969) were used as recipients for cloning or complementation experiments. E. coli $\mathrm{K} 12-\mathrm{Nl}$ was a spontaneous nalidixic acid-resistant mutant of E. coli C600 (Appleyard, 1954).

Strains were routinely grown at $37^{\circ} \mathrm{C}$ in tryptic soy broth (TSB) or on tryptic soy agar (TSA; Diagnostics Pasteur). When required, antibiotics were added at the following concentrations: ampicillin (Ap), $100 \mu \mathrm{g} \mathrm{ml}^{-1}$; chloramphenicol (Cm), $30 \mu \mathrm{g} \mathrm{ml}^{-1}$; kanamycin $(\mathrm{Km}), 50 \mu \mathrm{g} \mathrm{ml}^{-1}$; nalidixic acid (Nl), $100 \mu \mathrm{g} \mathrm{ml}^{-1}$; spectinomycin (Sp), $100 \mu \mathrm{g} \mathrm{m}^{-1}$; tetracycline (Tc), $20 \mu \mathrm{g} \mathrm{ml}^{-1}$.

Plasmids pUC18/19 $\left(\mathrm{Ap}^{\mathbf{R}}\right.$; Vieira \& Messing, 1982), and pGB2 $\left(\mathrm{Sp}^{\mathrm{R}}\right.$; Churchward et al., 1984) were used as cloning vehicles. Plasmid pRK2073 $\left(\mathrm{Sp}^{\mathrm{R}}\right.$; Ditta et al., 1980) was used as a helper plasmid in triparental plate matings to mobilize plasmid pVT1. Plasmid pVT1 was a recombinant mobilizable-plasmid harbouring the viaB locus of $S$. typhi $\mathrm{Ty} 2\left(\mathrm{Tc}^{\mathrm{R}}\right.$; Kolyva et al., 1992). This plasmid conferred a Vi-positive phenotype upon $E$. coli strains. Plasmid pVT1 was used as a source of DNA for construction of recombinant plasmids presented on Fig. 1. Construction of plasmids pVT22 to pVT28 was reported previously (Kolyva et al., 1992).

Plasmid pUC4K (Pharmacia) which carried the aminoglycoside 3 '-phosphotransferase $(a p b)$ gene, was used as a source of the $\mathrm{Km}$-cassette. From this plasmid, a second $\mathrm{Km}$-cassette carrying the aminoglycoside 3 '-phosphotransferase gene, but devoid of its transcription terminator $(a p b \Delta T)$, was constructed as described by Galan $e t$ al. (1992) and cloned into pUC18. The aph $\Delta T$ cassette was used to introduce non-polar mutations into the via $B$ locus on plasmid pVT1 and on the chromosome of $S$. typhi. Plasmid $\mathrm{pQF} 50 \mathrm{Cm}\left(\mathrm{Cm}^{\mathrm{R}} ; \mathrm{F}\right.$. Norel, unpublished) was a derivative of PQF50 (Farinha \& Kropinski, 1990) in which the ampicillin-resistance gene had been replaced by the chloramphenicol acetyltransferase (cat) gene of pACYC184 (Chang \& Cohen, 1978). A lac $Z$-cat cassette could be retrieved from PQF50Cm by using SalI restriction endonuclease. This cassette was used to study the transcription of the gene in which it had been inserted by monitoring $\beta$-galactosidase activity.

DNA manipulation and molecular cloning. Methods used for constructing and manipulating recombinant DNA were essentially those of Sambrook et al. (1989). Restriction endonucleases and nucleic acid-modifying enzymes were purchased from Amersham. Small-scale preparation of plasmid DNA was carried out as described by Birnboim \& Doly (1979) for E. coli strains and as described by Kado \& Liu (1981) for Salmonella strains. Plasmid transformation was performed in E. coli by the method of Humphreys et al. (1979) and in Salmonella by electroporation with a Bio-Rad apparatus according to the manufacturer's instructions. To study the distribution of tvi $A$ sequences among strains of Salmonella and Citrobacter by Southern blot analysis, an internal fragment of the tvi $A$ gene from $S$. typhi Ty2 was amplified by the polymerase chain reaction (PCR) with a commercial kit (Perkin-Elmer Cetus) using primers $5^{\prime}$-CCT CCG AAT GAT ATC TAT TTC GGG G- $3^{\prime}$ and $5^{\prime}$-ATC CGG CAA TAA CAG ATA GCG CGG C$3^{\prime}$. The probe was labelled with $\left[\alpha-{ }^{32} \mathrm{P}\right] \mathrm{dATP}$ by using a random primer labelling kit (Amersham). The tviA gene from S. typhi T643WSR was cloned into vector PGB2 after PCR amplification using primers 5'-GCT TCG CCG GCA TGC ATA AGG TAT 
TCA TTT- $3^{\prime}$ and $5^{\prime}$-TTC AAG AAT AAG CT'T TTT ATT AAC G-3' (Waxin et al., 1993).

A PCR clone encoding the RcsB protein of E. coli MC1061 was constructed by using primers 5'-ATG GCA AGG CGG ATC CGC 'TGG CAT TC'T GGC $-3^{\prime}$ and $5^{\prime}$-ATC CTG CTA AAG CTT TGC CGT CAA CGG ACA -3' (Stout \& Gottesman, 1990). The PCR fragment was cloned into vector PGB2 and the resulting plasmid was designated $\mathrm{pRcsB}$.

Construction of S. typhi viaB mutants. To study the individual contribution of each gene of the viaB locus to the Vi phenotype, the $a p h \Delta T$ cassette was cloned into unique sites of recombinant plasmids (from pVT22 through pVT28) presented on Fig. 1. The correct position of $a p b \Delta T$ insertion was verified by restriction mapping. The construction was transformed into $E$. coli MC1061 harbouring PVT1. The resultant strain was mated with E. coli C600 containing pRK2073 and E. coli K12-Nl as the recipient strain. Transconjugants were selected on $\mathrm{Nl}, \mathrm{Km}$ and Tc/TSA plates. Because the helper plasmid pRK2073 could mobilize only pVT1, homologous recombination between the wild-type gene to be mutated on pVT1 and the corresponding $a p b \Delta T$ allele on the recombinant plasmid was required to allow growth of E. coli $\mathrm{K} 12-\mathrm{Nl}$ transconjugants on $\mathrm{Km}$ - and Tccontaining plates. Transconjugants that had undergone correct recombination of the $a p h \Delta T$ cassette were identified by restriction analysis. Using this strategy, the $a p b \Delta T$ cassette was introduced into 10 ORFs of the viaB locus on pVT1. Each of the resulting plasmids was transformed into $S$. typhi Ty2.

Homologous recombination between the inactivated gene on pVT1 and the corresponding wild-type gene on $S$. typhi Ty2 chromosome was obtained as follows. $S$. typhi strains carrying pVT1 with a mutation in the given gene were inoculated into $10 \mathrm{ml}$ fresh TSB without antibiotics and transferred daily for $3 \mathrm{~d}$ in the same conditions. Cultures were isolated on $\mathrm{Km}$-plates and colonies were screened for their Tc-sensitivity. Double recombination was further confirmed by Southern analysis (data not shown). The mutated allele will be hereafter referred to as gene name::aph $\Delta T$ (e.g. $t v i B:: a p h \Delta T$ ).

The strategy described above was used to insert the $a p h$ cassette in the tvi $A$ gene, and the lac $Z$-cat cassette in the tvi $A$ or $t v i B$ gene on the chromosome of $S$. typhi.

Vi antigen assays. Presence of Vi antigen associated with cell surface was determined by slide-agglutination using Vi-specific antiserum (Diagnostics Pasteur) and further confirmed by lysis with the Vi-specific phage IV (Craigie \& Felix, 1947). Accumulation of intracellular $\mathrm{Vi}$ antigen or release of the polysaccharide into culture supernatant was demonstrated by immunoprecipitation as decribed previously (Kolyva et al., 1992). Using a highly purified preparation of $\mathrm{Vi}$ antigen (Typhim Vi; Institut Merieux), it was possible to detect as little as $0 \cdot 1 \mu \mathrm{g} \mathrm{ml}^{-1}$ soluble $\mathrm{Vi}$ antigen. It was verified that the commercial Vi-antiserum did not react with monomer or short oligomers of $\mathrm{Vi}$ antigen. For this purpose, a Vi antigendegrading enzyme was partially purified from the culture supernatant of Bacillus sphaericus ATCC 17932 following the procedure described by Baker \& Whiteside (1965). Incubation of $0.1 \mathrm{ml}$ enzyme solution with $5 \mu \mathrm{g}$ purified $\mathrm{Vi}$ antigen for $2 \mathrm{~h}$ at $35^{\circ} \mathrm{C}$ resulted in complete loss of serological reactivity of the polysaccharide in the immunoprecipitation assay.

Measurements of $\beta$-galactosidase activity. The assays for $\beta$ galactosidase activity were performed using overnight cultures as described by Miller (1972). Average values ( \pm 1 SD) of activity units were calculated based on at least three independent assays in each case.

\section{RESULTS}

\section{Vi polymer synthesis requires functional TviB, TviC, TviD and TviE polypeptides}

S. typhi Ty2 mutants in which the apb $\Delta T$ cassette had been inserted in the $t v i B, t v i C, t v i D$ or $t v i E$ genes were defective in $\mathrm{Vi}$ antigen synthesis. These mutants did not release $\mathrm{Vi}$ polymer in culture supernatant, were devoid of capsular polysaccharide at the cell surface, and did not accumulate polymer in their intracellular compartment (Table 1). Introduction of plasmid carrying only the homologous wild-type gene (Fig. 1 and Table 1) restored a Vi-positive phenotype to each mutant, which were slide-agglutinated by $\mathrm{Vi}$ antiserum and lysed by phage IV. These results demonstrated that TviB, TviC, TviD and TviE polypeptides were involved in $\mathrm{Vi}$ antigen synthesis. As Hashimoto et al. (1993) reported that TviA was not essential for $\mathrm{Vi}$ antigen production, we wondered whether TviB, TviC, TviD and TviE polypeptides were sufficient for Vi polymer synthesis. E. coli HB101 was transformed with different combinations of recombinant plasmids harbouring one or more of the tvi genes (Fig. 1), and the presence of intracellular $\mathrm{Vi}$ polymer was assayed by immunoprecipitation. Providing $t v i B$ and $t v i C$ in trans on plasmid pVT37 did not lead to Vi polymer synthesis in the intracellular compartment of E. coli HB101. Additional presence of $t v i D$ on plasmid $\mathrm{pVT} 31$ or of $t v i E$ on plasmid pVT32 did not affect the phenotype of E. coli HB101 carrying $\mathrm{PVT} 37$. In contrast, Vi polymer was detected in the intracellular compartment of $E$. coli $\mathrm{HB} 101$ harbouring $t v i B$ and $t v i C$ on plasmid pVT37 and $t v i D$ and tviE on plasmid pVT39. The results demonstrated that Vi polymer synthesis in the intracellular compartment of $E$. coli $\mathrm{HB} 101$ required functional $\mathrm{TviB}, \mathrm{TviC}, \mathrm{TviD}$ and TviE proteins.

\section{Vex proteins direct cell surface translocation and localization of Vi polysaccharide}

Insertion of the apb $\Delta T$ cassette in vex $A$, vex $B$ or vex $C$ on $S$. typhi Ty2 chromosome caused intracellular accumulation of Vi polysaccharide (Table 1). The mutants failed to elaborate cell surface-associated Vi antigen or to release it in the culture supernatant. These defects were complemented by recombinant plasmids bearing the homologous wild-type gene (Fig. 1 and Table 1). The results strongly suggested that VexA, VexB and VexC products were involved in translocation of $\mathrm{Vi}$ polymer to the bacterial surface. Interestingly, since the commercial Vi antiserum used did not react with monomers and oligomers of $\mathrm{Vi}$ antigen (see Methods), these results indicated that in vivo synthesis of full-length $\mathrm{Vi}$ polysaccharide chains could occur independently of chain translocation.

Immunoreactive $\mathrm{Vi}$ polysaccharide was detected in the intracellular compartment of cells and in the culture

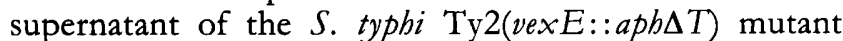
(Table 1). Polymeric material was apparently not present at the cell surface in this mutant. Introduction of plasmid pVT36 led to the detection of Vi antigen at the cell surface by slide-agglutination (Fig. 1 and Table 1). Thus, the 
Table 1. Phenotypes of non-polar S. typhi Ty2 viaB mutants

\begin{tabular}{|c|c|c|c|c|c|}
\hline \multirow[t]{2}{*}{ S. typhi Ty2 mutant } & \multicolumn{3}{|c|}{$\begin{array}{l}\text { Detection of Vi } \\
\text { polysaccharide* }\end{array}$} & \multirow{2}{*}{$\begin{array}{c}\text { Agglutination } \\
\text { by } 0: 9 \\
\text { antiserum }\end{array}$} & \multirow{2}{*}{$\begin{array}{c}\text { Plasmid } \oint \\
\text { used for } \\
\text { complementation }\end{array}$} \\
\hline & Intra & Cell & Super & & \\
\hline tvi $A:: a p h \Delta T$ & $(+)$ & $(+)$ & $(+)$ & + & pVT21 \\
\hline$t v i B:: a p b \Delta T$ & - & - & - & + & pVT29 \\
\hline$t v i C:: a p h \Delta T$ & - & - & - & + & pVT30 \\
\hline$t v i D:: a p h \Delta T$ & - & - & - & + & pVT31 \\
\hline$t v i E:: a p h \Delta T$ & - & - & - & + & pVT32 \\
\hline $\operatorname{vex} A:: a p b \Delta T$ & + & - & - & + & pVT33 \\
\hline vexB::aph $\Delta T$ & + & - & - & + & pVT34 \\
\hline $\operatorname{vex} C:: a p h \Delta T$ & + & - & - & + & pVT35 \\
\hline$v e x E:: a p b \Delta T$ & + & - & + & + & pVT36 \\
\hline ORF11::aph $\Delta T$ & + & + & + & - & None \\
\hline
\end{tabular}

* Detection of Vi polysaccharide at the cell surface (cell) by slide-agglutination, and in intracellular compartment (intra) or in culture supernatant (super) by immunoprecipitation. + , Positive; - , negative; $(+)$, weak reaction.

s See Fig. 1.

VexE protein appeared to be required for anchoring $\mathrm{Vi}$ antigen at the bacterial surface.

The $S$. typhi Ty2(ORF11::aphsT) mutant retained a Vipositive phenotype (Table 1 ). It was slide-agglutinated by $\mathrm{Vi}$ antiserum and lysed by phage IV. This result suggested that ORF11 was not required for Vi antigen synthesis, nor for the translocation of the polymer to the cell surface.

\section{TviA protein is required for co-transcription of tviA and tviB genes}

The S. typhi Ty2 mutant in which the $a p b \Delta T$ cassette had been inserted in the tvi $A$ gene was weakly agglutinated with $\mathrm{Vi}$ antiserum (Table 1), but unlike the parent strain Ty2, this mutant was agglutinated with $O: 9$ antiserum indicating that the $\mathrm{Vi}$ polysaccharide was no longer masking the lipopolysaccharide antigen. This observation suggested that $\mathrm{Vi}$ antigen synthesis was decreased in the tvi $A$ mutant. Indeed, as measured with the immunoprecipitation assay, the amount of $\mathrm{Vi}$ antigen produced by the $S$. typhi Ty2(tvi $A:: a p h \Delta T)$ mutant $\left(1 \cdot 1 \mu \mathrm{g} \mathrm{m}^{-1}\right)$ was 20 -fold less than that produced by $S$. typhi Ty2 $\left(23.5 \mu \mathrm{g} \mathrm{ml}^{-1}\right.$ ). Introduction of plasmid pVT21 (Fig. 1) fully restored a Vi-positive phenotype to $S$. typhi

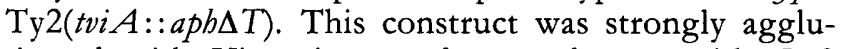
tinated with $\mathrm{Vi}$ antiserum, but no longer with O:9 antiserum, and produced $41.5 \mu \mathrm{g} \mathrm{Vi}$ antigen $\mathrm{ml}^{-1}$. These results demonstrated that the TviA polypeptide was not essential for $\mathrm{Vi}$ antigen synthesis, and suggested that TviA might be involved in Vi antigen expression.

To determine the effect of TviA product on $\mathrm{Vi}$ antigen expression, we inserted the lac $Z$-cat cassette into the tviB gene which is involved in Vi polysaccharide synthesis. $\beta$ Galactosidase activities of tviB::lac $Z$ transcriptional fusions were measured in overnight TSB cultures of $S$. typhi Ty2 mutants. Results are shown in Table 2. S. typhi Ty2(tviB::lacZ-cat) expressed about 200 Miller units.
Expression of the $t v i B:: l a c Z$-cat fusion was dramatically decreased when the tvi $A$ gene was disrupted by the nonpolar $a p b \Delta T$ cassette. Providing tvi $A$ in trans on plasmid pVT21 in $S$. typhi Ty2(tvi $A:: a p b \Delta T$, tviB::lacZ-cat) fully restored expression of the fusion. This result showed that TviA polypeptide was required for $t v i B$ gene transcription. In an attempt to unravel the role of TviA on tviB transcription, the tvi $A$ gene was disrupted by the $a p h$ cassette. This polar mutation was further recombined in tvi $A$ on the chromosome of $S$. typhi Ty2(tviB::lacZ-cat), yelding the double mutant $S$. typhi Ty2(tvi $A: a p h$, $t v i B:: l a c Z-c a t)$. As expected, disruption of the tvi $A$ gene by the $a p b$ cassette resulted in little expression of the tviB:: lac Z-cat fusion (Table 2). In contrast to results obtained for the S. typhi Ty2(tvi $A:: a p h \Delta T, t v i B:: l a c Z-c a t)$ mutant which carried a non-polar mutation in tvi $A$, introduction of plasmid pVT21 did not restore expression of the tviB::lacZ-cat fusion in S. typhi Ty2(tviA::aph, tviB::lacZ-cat) which carried a polar mutation in tvi $A$ (Table 2). Together, these results suggested that the tvi $A B$ genes were co-transcribed from a TviA-inducible promoter. As a test for $t v i A B$ co-transcription, plasmid pVT40 which carried the $t v i B$ coding sequence oriented in a head-to-tail manner with the lac promoter of the cloning vector (Fig. 1), was transformed into $S$. typhi Ty2(tviB::aph $\Delta T$ ). Contrary to plasmid pVT29 (Fig. 1 and Table 1), plasmid pVT40 failed to restore a Vipositive phenotype to this mutant, thereby confirming that $t v i A$ and $t v i B$ genes were likely to be co-transcribed in S. typhi Ty2.

\section{TviA protein is an activator of its own synthesis}

In an attempt to study the role of the TviA protein on its own promoter, experiments were conducted with the lac $Z$-cat cassette integrated in the BglII site of tvi $A$ on 


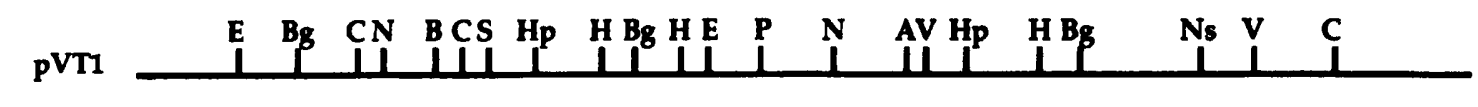

$1 \mathbf{k b}$

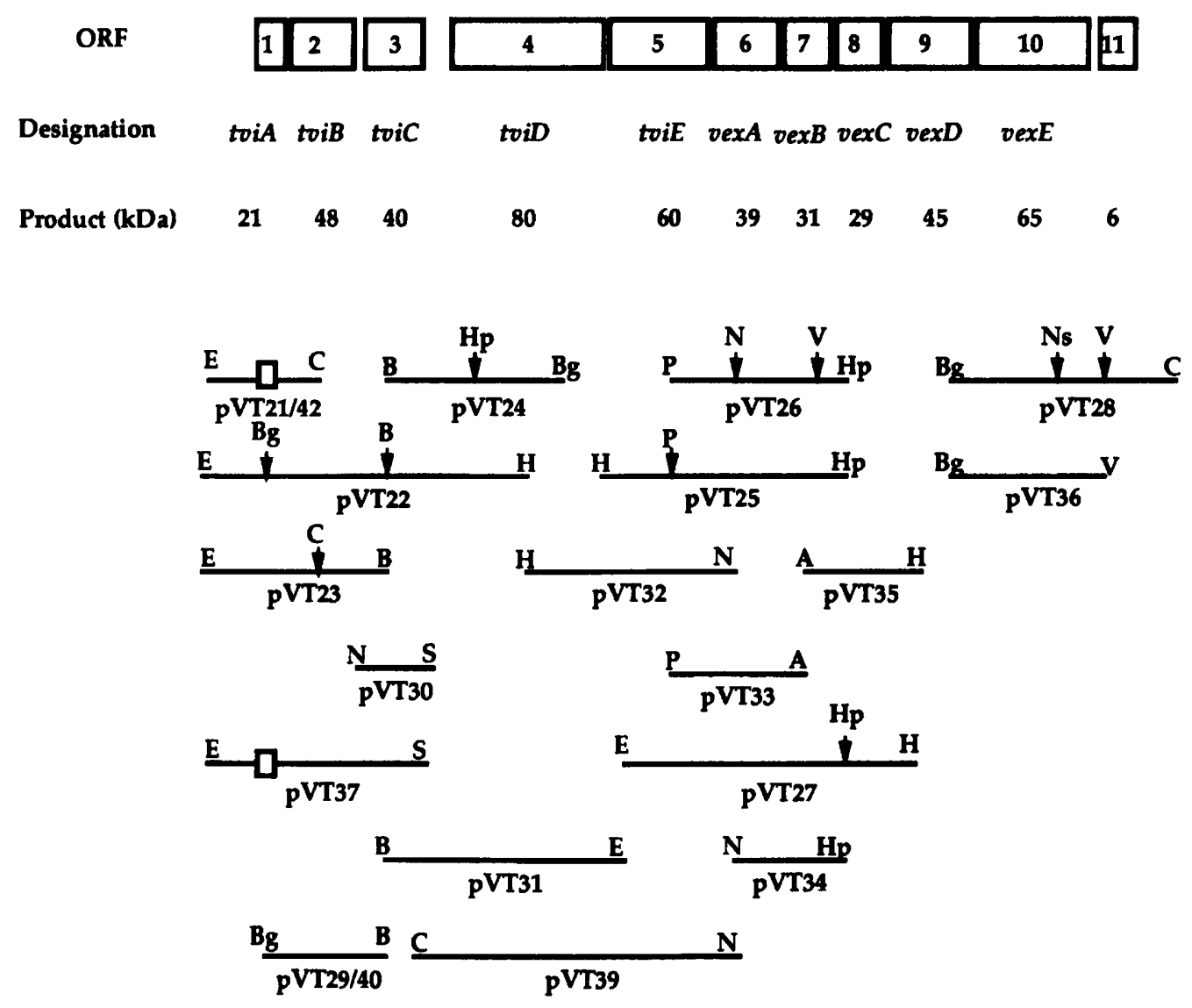

Fig. 1. Physical map of plasmid pVT1 and pVT1 subclones. Position and designation of ORFs, and molecular mass ( $\mathrm{kDa}$ ) of the corresponding products are indicated below the restriction map of pVT1. Recombinant subclones derived from pVT1 were constructed using pUC18/19 as a vehicle, except pVT21 and pVT37, which were constructed using pGB2. In pUC18/19-derivatives, the inserted fragments were oriented so that they might be transcribed from the plasmid lac promoter, except for plasmid pVT40 in which the inserted fragment was oriented in a head-to-tail manner with the lac promoter. The Bg/ll restriction site located within the tviA coding sequence was filled-in (box) in plasmid pVT37 and pVT42. Vertical arrows indicate restriction sites in which an aph $\Delta T$ cassette was inserted so as to construct non-polar mutants. Only relevant restriction sites are indicated: A, Accl; B, BamHI; Bg, Bglll; C, Clal; E, EcoRI; H, HindIII; Hp, Hpal; N, Ncol; Ns, Nsil; P, Pstl; S, Sphl; V, EcoRV.

the $S$. typhi $\mathrm{Ty} 2$ chromosome. $\beta$-Galactosidase activities were measured in overnight TSB cultures. $S$. typhi Ty2(tvi $A$ : : lac $Z$-cat) expressed about 60 Miller units. This $\beta$-galactosidase level increased tenfold in the presence of plasmid pVT21 (Table 2). In contrast, introduction of plasmid pVT42, a derivative of pVT21 in which the tviA coding sequence was disrupted by filling-in the $B g / \mathrm{II}$ site (Fig. 1), did not restore $\beta$-galactosidase activity to $S$. typhi Ty2(tvi $A$ : : lac $Z$-cat) (Table 2). This observation showed that extra copies of $t v i A$ DNA did not lead to activation of chromosomal tvi $A$ : : lac $Z$ fusion by binding a negative regulator. Together, these results indicated that $t v i A$ was transcribed at a basal level in the absence of TviA and that TviA protein was an activator of its own synthesis in S. typhi Ty2.

\section{RcsB protein acts as a positive regulator for co- transcription of tviA and tviB genes}

It was shown that the Vi-negative strain T643WSR was a via $A$ mutant of $S$. typhi (Johnson et al., 1966) and that via $A$ from $S$. typhi was allelic to $\operatorname{rcs} B$ from $E$. coli (Houng et al., 1992). As expected from these data, providing E. coli $\operatorname{rcs} B$ gene in trans on plasmid $\mathrm{pRcsB}$ restored a $\mathrm{Vi}$-positive phenotype to $S$. typhi T643WSR. As RcsB protein acted as a positive trans-acting regulator of capsule synthesis in $E$. coli (Gottesman \& Stout, 1991), we further examined the potential role of $\mathrm{RcsB}$ on the expression of the tvi $A B$ genes in $S$. typbi. Since TviA was required for trancription of tvi $A B$ genes, the lac $Z$-cat cassette was inserted in tviB on the chromosome of strain T643WSR. Expression of 
Table 2. $\beta$-Galactosidase activity expressed by lacz transcriptional fusions in S. typhi Ty2 mutants harbouring the indicated plasmids

\begin{tabular}{|c|c|c|}
\hline S. typhi Ty 2 mutant & Plasmid* & $\begin{array}{c}\beta \text {-Galactosidase } \\
\text { activity }\end{array}$ \\
\hline tviB: :lac $Z-c a t$ & None & $228 \pm 21$ \\
\hline tviB: : lac Z-cat & pGB2 & $217 \pm 17$ \\
\hline tviB: : lacZ-cat & pVT29 $\left(t v i B^{+}\right)$ & $201 \pm 33$ \\
\hline $\begin{array}{l}\text { tvi } A:: a p b \Delta T, \\
\text { tviB::lacZ-cat }\end{array}$ & None & $7 \pm 1$ \\
\hline $\begin{array}{l}\text { tvi } A:: a p h \Delta T, \\
\text { tviB::lacZ-cat }\end{array}$ & pGB2 & $8 \pm 2$ \\
\hline $\begin{array}{l}\text { tviA::aph } T, \\
\text { tviB::lacZ-cat }\end{array}$ & $\mathrm{pVT} 21\left(t v i A^{+}\right)$ & $198 \pm 10$ \\
\hline $\begin{array}{l}\text { tviA::aph, } \\
\text { tviB::lacZ-cat }\end{array}$ & None & $2 \pm 1$ \\
\hline $\begin{array}{l}\text { tvi } A:: a p h, \\
\text { tviB::lacZ-cat }\end{array}$ & pGB2 & $4 \pm 2$ \\
\hline $\begin{array}{l}\text { tvi } A:: a p h, \\
\text { tviB::lacZ-cat }\end{array}$ & $\mathrm{pVT} 21\left(t v i A^{+}\right)$ & $26 \pm 3$ \\
\hline tviA::lacZ-cat & None & $56 \pm 15$ \\
\hline tvi $A::$ lac $Z-c a t$ & pGB2 & $61 \pm 9$ \\
\hline tvi $A::$ lac $Z-c a t$ & $\mathrm{pVT} 21\left(t v i A^{+}\right)$ & $556 \pm 34$ \\
\hline tvi $A:$ : lac $Z-c a t$ & pVT42 (tviA) & $54 \pm 7$ \\
\hline
\end{tabular}

* See Fig. 1. The allele present on the recombinant plasmids is indicated in parentheses.

this transcriptional fusion was measured in overnight TSB cultures of $S$. typhi T643WSR (tviB:: lac $Z-c a t)$. In this strain, the tviB::lac $Z$-cat fusion was expressed at a very low level ( $3 \pm 1$ Miller units). Providing the E. coli rcsB gene in trans on plasmid $\mathrm{pRcsB}$ increased expression of this fusion to the level measured in $S$. typhi Ty2(tviB::lacZ-cat), i.e. $182 \pm 7$ versus $228 \pm 21$ Miller units, respectively. To preclude the possibility that $\operatorname{rcs} B$ in multicopy on plasmid $\mathrm{pRcsB}$ might bypass a tvi $A$ mutation, we cloned the tvi $A$ gene of strain T643WSR to examine whether it was intact in this mutant. The resulting recombinant plasmid restored a $\mathrm{Vi}$-positive phenotype to Ty2(tvi $A:: a p h \Delta T)$ mutant, confirming that the tvi $A$ gene was functional on the chromosome of $S$. typhi T643WSR. Thus, these results demonstrated that RcsB polypeptide was involved in $t v i A B$ transcription.

Unexpectedly, presence of tvi $A$ in multicopy on plasmid pVT21 increased expression of the tviB:: lacZ-cat fusion in the $S$. typhi T643WSR mutant (115 \pm 28 Miller units). This increase suggested that the requirement for RcsB for tvi $A B$ co-transcription could be at least partially bypassed by tvi $A$ multicopies. Thus, plasmid pVT21 was transformed into $S$. typhi T643WSR. In this construct, Vi antigen was detected in the intracellular compartment, at the cell surface and in the culture supernatant. This result confirmed that TviA expressed from multicopy plasmid could bypass an $r c s B$ mutation in $S$. typhi. Since RcsB was not essential when TviA was overproduced, we wondered whether TviA was essential when RcsB was produced

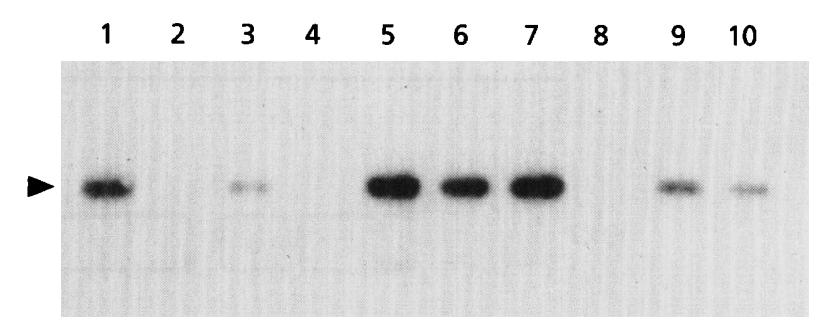

Fig. 2. Hybridization of the tviA DNA probe to total-cell DNA from Salmonella and Citrobacter strains. Lanes contain DNA digested with EcoRI and Clal from: 1, S. typhi Ty2 $(\mathrm{Vi}+)$; 2, C. freundii CNS (Vi-); 3, plasmid pVT1 (control); 4, S. typhimurium C5 ( Vi-); 5, S. typhi T643 $(\mathrm{Vi}-)$; 6, S. paratyphi C 1535K $(\mathrm{Vi}+) ; 7$, S. paratyphi C 32K $(\mathrm{Vi}+) ; 8$, S. dublin $228 \mathrm{~K}$ $(\mathrm{Vi}-)$; 9, S. dublin 1662K ( $\mathrm{Vi}+) ; 10$, C. freundii $7851(\mathrm{Vi}+)$. Arrowhead to the left denotes the position of the $2 \cdot 1 \mathrm{~kb}$ fragment containing the tviA locus.

from a multicopy plasmid. For this purpose, plasmid $\mathrm{pRcsB}$ was introduced into $S$. typhi $\mathrm{Ty} 2(t v i A:: a p b \Delta T)$. The resultant strain synthesized low amounts of $\mathrm{Vi}$ antigen and remained agglutinated by $O: 9$ antiserum. Moreover,

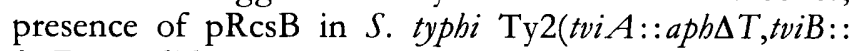
lac $Z$-cat $)$ did not increase expression of the lac $Z$ fusion ( $4 \pm 1$ Miller units). These results demonstrated that TviA was required for full expression of $\mathrm{Vi}$ antigen even when RcsB was expressed from a multicopy plasmid.

\section{Conservation of tviA sequence among Vi-expressing strains of Salmonella and Citrobacter}

To test for the presence of tvi $A$ or tvi $A$-like sequences in Vi-expressing strains of Salmonella and Citrobacter, Southern blot hybridization analysis was performed using total DNA samples digested with EcoRI and ClaI restriction endonucleases. The probe, generated by PCR amplification, corresponded to an internal fragment of the tviA gene from $S$. typbi Ty2. Result of this analysis is shown in Fig. 2. The $2.1 \mathrm{~kb}$ EcoRI-ClaI fragment containing tvi $A$-homologous sequence (Fig. 1) was present in all Vi-positive strains of Salmonella and Citrobacter, and in the Vi-negative $S$. typhi T643WSR mutant. This sequence was not detected in the Vi-negative strains of $S$. typhimurium $\mathrm{C} 5, S$. dublin $228 \mathrm{~K}$ or $C$. freundii CNS. These results indicated that regions of high sequence similarity to $S$. typhi tvi $A$ gene were conserved among Vi-expressing strains of Salmonella and Citrobacter.

\section{DISCUSSION}

\section{Synthesis of the Vi polysaccharide}

The bacterial capsular polysaccharides are classified into two groups (designated I and II) by chemical, physical and genetic criteria (Jann \& Jann, 1990). In general, group I polysaccharides have high molecular masses, contain uronic acid as the acidic component, are expressed below $20^{\circ} \mathrm{C}$, and are co-expressed with specific $\mathrm{O}$ polysaccharides. The Vi antigen of $S$. typhi shares all these 
structural and biochemical properties and might therefore be considered as a group I polysaccharide. Little is known about the biosynthesis of group I polysaccharides. Production of capsular polysaccharides begins with the synthesis of sugar components which are converted to nucleotide derivatives in the cytoplasmic compartment. The subsequent polymerization is catalysed by an innermembrane-bound transferase complex. Generally, polymerization is believed to involve a lipid carrier on which monosaccharides or oligosaccharides are assembled (Boulnois \& Roberts, 1990). In addition, this lipid substitution is required for translocation of the polysaccharide to the bacterial cell surface (Frosch \& Müller, 1993).

The via $B$ locus of $S$. typhi is composed of 11 genes designated tvi $A-E$, vex $A-E$ and ORF11. Results presented in this communication confirm that TviB and TviC polypeptides are required for the synthesis of $\mathrm{Vi}$ polysaccharide chains. On the basis of primary sequence similarity and identification of a potential dinucleotidebinding site, Hashimoto et al. (1993) proposed that tviB and tviC might encode the NAD- or NADP-dependent enzymes required to synthesize the nucleotide sugar for the Vi polysaccharide synthesis. Their view is supported by our data based on the phenotypes of tviB and tviC mutants and complementation experiments (Table 1). In addition, the TviE and TviD polypeptides are required for synthesis of $\mathrm{Vi}$ antigen (Table 1). Recent comparison of the amino acid sequence of TriE with the Swiss-Prot database (release 29) showed that the C-terminal domain of TviE possesses a significant level of homology to UDP-galactosyltransferases of prokaryotic and eukaryotic organisms. Based on this similarity and on results presented in Table 1, we suggest that TviE may be the transferase required for $\mathrm{Vi}$ polymerization. The function of the TviD product remains unclear. A non-polar tviD mutant of S. typhi Ty2 failed to synthesize detectable Vi antigen (Table 1). In contrast, Vi polysaccharide was detected in the cytoplasmic compartment of E. coli HB101 carrying multicopies of the viaB locus in which the $t v i D$ coding sequence had been disrupted by a transposon insertion and in which the transport system was functional (Kolyva et al., 1992; Hashimoto et al., 1993). These latter observations suggest that TviE expressed from a multicopy plasmid could initiate polymerization of the $\mathrm{Vi}$ polysaccharide in the absence of TviD, but that these $\mathrm{Vi}$ chains are not recognized by the components of the translocation system. From these data, it is tempting to speculate that the TviD protein is the endogenous lipid carrier essential for the initiation of $\mathrm{Vi}$ polymer synthesis by the TviE protein and for the polysaccharide translocation to the bacterial cell surface. This mechanism is still speculative and direct biochemical assays to confirm this hypothesis are presently underway in our laboratory.

\section{Translocation of the Vi polysaccharide to the bacterial cell surface}

The transport systems of group II capsular polysaccharides in Gram-negative bacteria fit the characteristics of the $\mathrm{ABC}$ (ATP-binding cassette) active trans- porters (Frosch et al., 1991; Higgins, 1992; Kroll et al., 1990). Proteins VexA, VexB, VexC and VexD encoded by the viaB locus of $S$. typhi shared similarities with components of $\mathrm{ABC}$ transporters (Hashimoto et al., 1993; Waxin et al., 1993). Indeed, non-polar mutation in vex $A$, vex $B$ or vexC gene of $S$. typhi Ty2 caused intracellular accumulation of $\mathrm{Vi}$ polymer. Thus, it appears that the Vex A, B and C polypeptides are components of the $\mathrm{Vi}$ polysaccharide export apparatus in $S$. typhi, and probably belong to the $\mathrm{ABC}$ transporter family.

In E. coli, the periplasmic KpsD protein is necessary for the cell surface expression of the K1 capsule, a group II capsular polysaccharide. A chromosomal mutation in kps $D$ resulted in loss of surface expression of the K1 capsule (Silver et al., 1987). Like KpsD, the VexE protein is a hydrophilic protein (Hashimoto et al., 1993) with positively charged residues throughout the sequence (unpublished data), which may be relevant to interaction with the negatively charged $\mathrm{Vi}$ polysaccharide. In the vexE mutant of $S$. typhi Ty2, the Vi polymer was detected in the intracellular compartment and in the culture supernatant, but was undetectable at the bacterial cell surface (Table 1). However, no homology was detected between $\mathrm{KpsD}$ and VexE proteins and the amino-terminal region of VexE did not contain a characteristic signal sequence required for secretion to the periplasmic space.

Together, these data suggest that a conserved mechanism may exist for the energy-dependent translocation of group I and group II capsular polysaccharides in Gram-negative bacteria.

\section{Regulation of $\mathrm{Vi}$ antigen expession}

The tvi $A$ gene of the via $B$ locus encodes a $21 \mathrm{kDa}$ protein which shares no significant homology with available sequences in databases (Hashimoto et al., 1993; Waxin et al., 1993). Though not essential for Vi polymer synthesis (Table 1; Hashimoto et al., 1993), the TviA protein was required for full expression of $\mathrm{Vi}$ antigen. Indeed, disrupting the tvi $A$ coding sequence on the chromosome of $S$. typhi by a non-polar cassette resulted in little expression of the polysaccharide. This defect was transcomplemented when tviA was provided on multicopy plasmid (Table 1). By using lac $Z$ transcriptional fusions, we provided evidence that the transcription of the tviA and $t v i B$ genes proceeded from a promoter located upstream of $t v i A$ coding sequence (Table 2). In addition, it was shown that $t v i A$ was expressed at a low basal level in the absence of TviA protein. Expression of tviA increased tenfold upon introduction of TviA-expressing plasmid pVT21 (Table 2). Together, these results strongly suggest that $t v i A$ and $t v i B$ are co-transcribed from a TviAregulated promoter.

The via $A$ product is also required for $\mathrm{Vi}$ antigen expression in S. typhi (Houng et al., 1992). Since viaA from $S$. typhi is allelic to $r c s B$ from $E$. coli, it is likely that $\mathrm{Vi}$ antigen expression is regulated at least partially by a system similar to the rcs regulatory system involved in colanic acid synthesis in E. coli (Gottesman \& Stout, 1991; Houng et al., 1992). The 60 -fold increase of $\beta$ - 
galactosidase activity expressed by the $S$. typhi T643WSR(tviB: : lacZ-cat) mutant, when the E. coli rcsB gene was provided in trans on a multicopy plasmid, confirmed that RcsB or a RcsB-like protein was required for the tvi $A B$ gene transcription in $S$. typhi. Since the chromosomal tvi $A$ gene was shown to be functional in $S$. typhi T643WSR, the fact that over-expression of TviA from a multicopy plasmid restored a Vi-positive phenotype to this strain, however, suggested that a high copy number of the tvi $A$ gene could bypass the regulatory pathway involving the via $A$ product. However, we observed that TviA did not contain a domain with any similarity to the C-terminal DNA-binding domain of RcsB. On the basis of results presented here, it is tempting to speculate that both TviA and ViaA (or RcsB) products act as positive regulators for $\mathrm{Vi}$ antigen synthesis by transcriptionally activating the tvi $A B$ genes, either directly or indirectly. The precise mechanism of tvi $A$ and via $A$ activity in modulating $\mathrm{Vi}$ antigen expression remains to be elucidated. Interestingly, regions of high sequence similarity to the tviA gene of $S$. typhi were detected in Citrobacter strains and other Salmonella serovars expressing the $\mathrm{Vi}$ antigen.

Given the complexity of capsule synthesis regulation and the diversity of microenvironment encountered by $S$. typhi within the host, it is not surprising that various regulatory circuits up- or down-regulate expression of the virulence-associated $\mathrm{Vi}$ antigen. Analysis of the possible interaction between the rcs system, the $o m p R-e n v Z$ regulon and the TviA protein should provide new insights into the transcriptional events modulating $\mathrm{Vi}$ antigen expression in S. typhi.

\section{ACKNOWLEDGEMENTS}

We thank F. Norel and R. Ferrero for critical review of this manuscript.

\section{REFERENCES}

Appleyard, R. K. (1954). Segregation of new lysogenic types during growth of a double lysogenic strain derived from Escherichia coli K12. Genetics 39, 440-452.

Baker, E. E. \& Whiteside, R. E. (1965). Preparation and properties of a $\mathrm{Vi}$ antigen-degrading enzyme. $J$ Bacteriol 89, 1217-1224.

Baker, E. E., Whiteside, R. E., Basch, R. \& Derow, M. A. (1959). The $\mathrm{Vi}$ antigen of the Enterobacteriaceae. II. Immunologic and biologic properties. J Immunol 83, 680-686.

Birnboim, H. C. \& Doly, J. (1979). A rapid alkaline extraction procedure for screening recombinant plasmid DNA. Nucleic Acids Res 7, 1513-1523.

Boulnois, G. J. \& Roberts, I. S. (1990). Genetics of capsular polysaccharide production in bacteria. Curr Top Microbiol Immunol 150, 1-18.

Boyer, H.W. \& Roulland-Dussoix, D. A. (1969). A complementation analysis of the restriction and modification of DNA in Escherichia coli. J Mol Biol 41, 459-472.

Casadaban, M. \& Cohen, S. N. (1980). Analysis of a gene control signal by DNA fusion and cloning in E. coli. J Mol Biol 138, 179-207.

Chang, A. C. Y. \& Cohen, S. N. (1978). Construction and charac- terization of amplifiable multicopy DNA cloning vehicles derived from p15A cryptic miniplasmid. J Bacteriol 134, 1141-1155.

Churchward, G., Belin, D. \& Nagamine, Y. (1984). A pSC101derived plasmid which shows no sequence homology to other commonly used cloning vectors. Gene 31, 165-171.

Craigie, J. \& Felix, A. (1947). Typing of typhoid bacilli with Vi bacteriophage. Lancet i, 824-827.

Daniels, E. M., Schneerson, R., Egan, W. M., Szu, S. C. \& Robbins, J. B. (1989). Characterization of the Salmonella paratyphi C Vi polysaccharide. Infect Immun 57, 3159-3164.

Ditta, G., Stanfield, S., Corbin, D. \& Helinski, D. R. (1980). Broad host range DNA cloning system for Gram-negative bacteria: construction of a gene bank of Rbizobium meliloti. Proc Natl Acad Sci US A 77, 7347-7351.

Farinha, M. A. \& Kropinski, A. M. (1990). Construction of broadhost-range plasmid vectors for easy visible selection and analysis of promoters. J Bacteriol 172, 3496-3499.

Felix, A. \& Pitt, R. M. (1934). A new antigen of B. typhosus. Lancet 227, 186-191.

Felix, A. \& Pitt, R. M. (1936). The Vi antigens of various Salmonella types. Br J Exp Pathol 17, 81-86.

Frosch, M. \& Muller, A. (1993). Phospholipid substitution of capsular polysaccharides and mechanisms of capsule formation in Neisseria meningitidis. Mol Microbiol 8, 483-493.

Frosch, M., Edwards, U., Bousset, K. Krauße, B. \& Weisgerber, C. (1991). Evidence for a common molecular origin of the capsule gene loci in Gram-negative bacteria expressing group II capsular polysaccharides. Mol Microbiol 5, 1251-1263.

Galan, J. E., Ginocchio, C. \& Costeas, P. (1992). Molecular and functional characterization of the invasion gene inv $A$ : homology of InvA to members of a new protein family. $J$ Bacteriol 174, 4338-4349.

Gottesman, S. \& Stout, V. (1991). Regulation of capsular polysaccharide synthesis in Escherichia coli K-12. Mol Microbiol 5, 1599-1606.

Hashimoto, Y., Ezaki, T., Li, N. \& Yamamoto, H. (1991). Molecular cloning of the viaB region of Salmonella typhi. FEMS Microbiol Lett 90, 53-56.

Hashimoto, Y., Li, N., Yokoyama, H. \& Ezaki, T. (1993). Complete nucleotide sequence and molecular characterization of $\mathrm{ViaB}$ region encoding Vi antigen in Salmonella typhi. J Bacteriol 175, 4456-4465.

Heyns, K. \& Kiessling, G. (1967). Strukturaufklarung des Viantigens aus Citrobacter freundii (E. coli) 5396/38. Carbohydr Res 3, 340-352.

Higgins, C. F. (1992). ABC transporters: from microorganisms to man. Annu Rev Cell Biol 8, 67-113.

Houng, H. H., Noon, K. F., Ou, J. T. \& Baron, L. S. (1992). Expression of $\mathrm{Vi}$ antigen in Escherichia coli $\mathrm{K}-12$ : characterization of $\mathrm{ViaB}$ from Citrobacter freundii and identity of $\mathrm{ViaA}$ with RcsB. $J$ Bacteriol 174, 5910-5915.

Humphreys, G. O., Weston, A., Brown, M. G. M. \& Saunders, J. R. (1979). Plasmid transformation in Escherichia coli. In Transformation, pp. 254-279. Edited by S. W. Glover \& L. O. Buttler. Oxford: Cotswold Press.

Jann, A. \& Jann, K. (1990). Structure and biosynthesis of the capsular antigens of Escherichia coli. Curr Top Microbiol Immunol 150, $19-42$.

Johnson, E. M. \& Baron, L. S. (1969). Genetic transfer of the Vi antigen from Salmonella typhosa to Escherichia coli. J Bacteriol 99, 355-359.

Johnson, E. M., Krauskopf, B. \& Baron, L. S. (1965). Genetic 
mapping of Vi and somatic antigenic determinants in Salmonella. $J$ Bacteriol 90, 302-308.

Johnson, E. M., Krauskopf, B. \& Baron, L. S. (1966). Genetic analysis of the viaA-bis chromosomal region in Salmonella. $J$ Bacteriol 92, 1457-1463.

Kado, C. I. \& Liu, S. T. (1981). A rapid procedure for detection and isolation of large and small plasmids. J Bacteriol 145, 1365-1373.

Kolyva, S., Waxin, H. \& Popoff, M. Y. (1992). The Vi antigen of Salmonella typhi: molecular analysis of the viaB locus. J Gen Microbiol 138, 297-304.

Kroll, J. S., Loynds, B., Brophy, L. N. \& Moxon, R. (1990). The bex locus in encapsulated Haemophilus influenzae: a chromosomal region involved in capsule polysaccharide export. Mol Microbiol 4, 1853-1862.

Le Minor, L. \& Nicolle, P. (1964). Sur deux souches de Salmonella dublin possédant l'antigène Vi. Ann Inst Pasteur 107, 550-556.

Miller, J. H. (1972). Experiments in Molecular Genetics. Cold Spring Harbor, NY: Cold Spting Harbor Laboratory.

Pickard, D., Li, J., Roberts, M., Maskell D., Hone, D., Levine, M., Dougan, G. \& Chatfield, S. (1994). Characterization of defined $o m p R$ mutants of Salmonella typhi:ompR is involved in the regulation of Vi polysaccharide expression. Infect Immun 62, 3984-3993.
Sambrook, J., Fritsch, E. F. \& Maniatis, T. (1989). Molecular Cloning: a Laboratory Manual, 2nd edn. Cold Spring Harbor, NY: Cold Spring Harbor Laboratory.

Silver, R. P., Aaronson, W. \& Vann, W. F. (1987). Translocation of capsular polysaccharides in pathogenic strains of Escherichia coli requires a 60-kilodalton periplasmic protein. J Bacteriol 169, 5489-5495.

Snellings, N. J., Johnson, E. M. \& Baron, L. S. (1977). Genetic basis of Vi antigen expression in Salmonella paratyphi C. J Bacteriol 131, $57-62$.

Stout, V. \& Gottesman, S. (1990). RcsB and RcsC: a twocomponent regulator of capsule synthesis in Escherichia coli. $J$ Bacteriol 172, 659-669.

Vieira, J. \& Messing, J. (1982). The pUC plasmids, an M13 mp7derived system for insertion mutagenesis and sequencing with synthetic universal primers. Gene 19, 259-268.

Waxin, H., Virlogeux, I., Kolyva, S. \& Popoff, M. Y. (1993). Identification of six open reading frames in the Salmonella enterica subsp. enterica ser. Typhi viaB locus involved in $\mathrm{Vi}$ antigen production. Res Microbiol 144, 363-371.

Received 22 May 1995; revised 7 August 1995; accepted 14 August 1995. 